\title{
HOW TO INSTITUTIONALIZE INNOVATIVE CLUSTERS? COMPARING EXPLICIT TOP-DOWN AND IMPLICIT BOTTOM-UP APPROACHES
}

Martina Fromhold-Eisebith \& Günter Eisebith

Dept. of Geography, Geology and Mineralogy

University of Salzburg, Austria

e-mail: martina.fromhold@sbg.ac.at

Paper to be presented at the conference 'Regionalization of Innovation Policy - Options and Experiences', Berlin, June 4-5, 2004, organized by the DIW Berlin 
"I'd rather be vaguely right than precisely wrong." (John Maynard Keynes)

\begin{abstract}
Soon after the concept of economic clusters became popular in the early 1990s aiming to explain national and (subnational) regional economic success, it has been picked up as a guideline for pro-actively promoting industrial competitiveness and innovativeness by fostering sectoral specialization and collaboration. Implementing and operationalizing clusters in a practical approach, however, is a complex task which actually requires to reflect on various issues, such as conceptual foundations, spatial scale, main objectives and institutional form of support, before respective measures get initiated. This paper focuses on the question of effective innovation-enhancing institutional forms of cluster promotion, indirectly also addressing other major issues. It discusses two opposite modes of institutionalization which both relate to the creation of regional cluster-related advantages: On the one hand, explicit cluster policies that are implemented top-down by regional authorities; on the other hand, implicit initiatives that emerge bottom-up from groups of sector-related firms without a concrete political impetus. The two approaches are compared from a theoretical perspective, looking at probable differences regarding the support of positive dynamics associated with the cluster idea. Additionally, an ongoing empirical project is introduced which investigates two initiatives that promote regionally concentrated automotive supply firms, in the Euregio Maas-Rhine (Germany/Netherlands/Belgium) and in Styria (Austria), the first one relating to the implicit bottom-up logic of support and the second one to the explicit top-down variant. The findings may support the assumption that different institutional modes of innovation-oriented cluster promotion display differing patterns and degrees of effectiveness and efficiency.
\end{abstract}

Keywords: Cluster policy, cluster promotion, regional economic promotion, institutions, innovation support, regional development. 


\section{Introduction}

The notion of cluster, despite its lack of profundity and conceptual clarity, as comprehensively outlined by Martin and Sunley (2003), has gained wide recognition as a model of industrial promotion and related policies on both national and regional levels (OECD, 1999 and 2001; European Commission, 2002). Critics are overrun by the strong appeal of the concept based on promised advantages of competitiveness and innovativeness that allegedly emerge from the spatial concentration of interacting firms and other organizations belonging to related industries or the same value chain (Held, 1996; Lagendijk, 1999; Mariussen, 2001, Raines, 2002a). A growing number of countries all over the world is inspired by such prospects and follows the trend, proactively engaging in cluster building. There are even 'manuals' that offer practical guidance for that task (Cluster Navigators Ltd., 2001; Rosenfeld, 2002). Many efforts are assisted by Michael Porter himself, who initiated the boom of the notion by his writings (e.g. Porter 1990, 1998, 2000a, 2000b), but has not invented its basic ideas. Yet the question which strategies probably achieve the best results depending on sectorand region-specific conditions is still widely unanswered (Raines, 2002b), although several studies have compared different modes of cluster support (Boekholt and Thuriaux, 1999; Roelandt et al, 2000; Raines, 2000 and 2001; European Commission, 2002).

As the cluster concept provides wide scope for interpretation due to its 'fuzzy' nature, the same can be said of cluster promotion. In fact the 'definitional incompleteness of the cluster concept has been an important reason for its popularity’ (Martin and Sunley, 2003, p. 9, referring to Perry, 1999). It offers almost unlimited options of application to various socio-economic and institutional settings on different spatial scales. This insight, however, should not prevent us from advocating an analytical perspective towards cluster promotion and policies. It seems possible to bring further a structured discussion on practices of cluster support which is to some extent set apart from the problem of conceptual obscurities (which, in contrast, does not apply to 'real' cluster identification, assessment and measurement which requires clear boundaries, benchmark values and 'templates'; Bergman and Lehner, 1998b). This paper highlights issues of cluster promotion without debating the cluster term itself (nevertheless we acknowledge that the conceptual debate is relevant for policy design).

In our context a cluster is quite broadly conceived as a spatial concentration of thematically related firms and other organizations (universities, research labs, public support agencies and others) which are interlinked on the base of business-related commonalities and complementarities and derive economic advantages from that (this appears to be a common denominator of various definitions; Martin and Sunley, 2003, p. 10-13; see also Steiner, 1998). We explicitly regard a cluster as a (subnational) regional phenomenon, not a national one, as per the crucial role of socially embedded interaction and spatial proximity for relevant processes. Yet, the cluster idea is less taken as a specifically defined notion here but rather as a symbolic terminological amalgamation of a set of ideas which have generally become standard objectives of innovation oriented regional development (Nauwelaers, 2001; Raines, 2001), and which are to some degree also captured by other notions of the 'family' of Territorial Innovation Models (Moulaert and Sekia, 2003). These objectives relate to economic benefits potentially derived by co-locating firms from vertical linkages in the value chain, horizontal relationships, and the interaction with education, $R \& D$ and other organizations nearby.

Due to the potential of such relationships to foster innovation and learning, clusters are seen as 'elements of wider regional or national innovation systems' (Tödtling, 2001, p. 60; see also Roelandt and den Hertog, 1999). This is why the concept has especially been used in the con- 
text of promoting high technology areas (e.g. Keeble and Wilkinson, 2000). Some evidence seems to confirm that clustered firms tend to be more innovative than non-clustered ones (Baptista and Swann, 1998; Baptista, 2000; European Commission, 2002), although other research raises objections (summarized in Martin and Sunley, 2003). At large, cluster promotion is conceived as a modern form of regional innovation policy, at least claims to also lead to effects of increased innovativeness (OECD, 1999 and 2001; Nauwelaers, 2001).

Against this backdrop the paper aims at contributing to a better understanding of innovation-oriented cluster promotion and to the development of effective strategies. After summarizing general suggestions and recommendations on cluster support to be found in the literature, a common framework is introduced that categorizes modes of cluster promotion with respect to certain institutional features. The main part of the paper then discusses in detail two opposite institutional forms which can be found in practice: Explicit cluster policies established top-down by regional governments are compared to initiatives which only implicitly refer to the cluster idea and are governed bottom-up by groups of industrial actors. Important questions are: Which fundamental differences characterize these approaches, and what are the consequences regarding the realization of cluster advantages? Which 'philosophy' of institutionalization promises to show better results, relating to which regional conditions? We argue that the two institutional forms of cluster promotion probably bear differing effects with regard to various aspects of the targeted community of firms/organizations, affecting regional innovation and economic success. This result might be of high political relevance, especially if the bottom-up way that hardly uses public financial support turned out to be more effective than the top-down approach.

In order to support the validity of this argument, the authors currently investigate two regions that can be associated with the juxtaposed institutional forms of cluster promotion, in both cases relating to automotive supply industries (Automotive Cluster Styria, Austria; car e.V. Euregio Maas-Rhein, Germany/Netherlands/Belgium). The paper provides an overview of project procedures. In conclusion, recommendations are derived regarding favorable institutional forms of cluster-related regional innovation policies.

\section{What is (regional) cluster promotion? Trying to be 'vaguely right'}

Renouncing an exact conceptual demarcation of cluster does not exempt us from explaining what should be captured under the notion of cluster promotion (just referring to the region-, not the nation-related interpretation of the term). This may be an easier task than to define a cluster which would actually require to identify threshold values with respect to intensities and qualities of collaboration, numbers or relative shares of included firms, involvement of other organizations, and certain manifestations of cluster effects (Martin and Sunley, 2003). Cluster promotion, in contrast, may more simply be delineated as any set of measures, in whatever constellation and style of implementation, that supports the development of specialized and competitive industrial structures of a region towards the ideal interaction features of a cluster, without setting specific thresholds regarding achievements. It is not only confined to policies that are designated and officially carry that popular label but also includes approaches which address similar objectives of supporting regional innovation and production systems in particular industries without drawing on the brand mark (see also Raines, 2001; Martin and Sunley, 2003); this allows to distinguish explicit and implicit cluster promotion.

The character of cluster strategies shows wide variations over regions and sectors, necessarily taking account of path-dependent place- and industry-specific conditions in terms of eco- 
nomic history and firm structure, institutional and infrastructural endowments (Raines, 2000 and 2001; Nauwelaers, 2001; OECD, 2001; European Commission, 2002). Hence, it is not possible to state all corresponding measures; they do not uniformly apply to all sets of circumstances. Generally, cluster promotion addresses several objectives in an integrated way. One focus is set on the improvement of firms' competitiveness (in line with Porter's earlier views; Porter, 1990 and 1998), which includes to expose them to stronger competition (for instance, through attracting foreign investors), improve their performance (consulting, training, innovation), raise the quality of suppliers and effective supply chain management, cater to high quality requirements of customers, and enhance the provision of certain inputs in terms of research, education and venture capital. Another focus (increasingly also adopted by Porter; Porter, 2000a and b), which is linked to the first one, emphasizes regional systemic effects, also bearing social processes in mind. Cluster promotion aims to stimulate and support the emergence of collaborations and strengthen interaction between various co-locating agents (Boekholt and Thuriaux, 1999). Some standard features of recommended best practice can be listed which provide a vague, however widely valid account (see also OECD, 2001; Raines, 2001; European Commission, 2002; Nolan, 2002; Martin and Sunley, 2003):

- As a rule, cluster promotion mainly builds upon and activates existing potential which requires the pre-existence of some regionally concentrated firms, other organizations and linkages in the target sectors. Thus, respective measures mainly aim at enriching and strengthening promising features of 'proto-clusters', helping them to unfold. A few emerging economies in Asia, in contrast, have established policies for newly creating clusters from scratch. At large, however, cluster researchers regard 'greenfield' strategies as not promising much success; therefore they are excluded from our discussion.

- Initiatives of cluster promotion usually try to facilitate the firms' access to various previously insufficiently used assets that support company performance and innovativeness, from public and private sources. This relates in particular to the following tasks:

- Fostering information exchanges and collaborative arrangements between regional firms and including other organizations which is expected to entail the pooling of resources, quality improvements and the creation of collective solutions and identities. Especially SMEs are addressed because they can most probably profit from complementary contributions by other firms and reduced transactions costs as they often lack professional in-house capabilities in various fields. The support of co-operation may serve to build up logistic, supply, marketing and distribution networks, provide access to various services, co-ordinate quality standards of products, organize cost-saving purchasing partnerships, or create special training schemes. Eventually, the entire regional value chain of the target sector could get restructured and streamlined, including the emergence of spin-off firms, mergers or firm closures;

- Establishing innovation-enhancing links of firms to regional universities and R\&D organizations which serve as channels for the commercialization of research results and technology transfer, create product and process innovations and positively influence the knowledge management of firms. In addition to facilitating access to $R \& D$, contacts to higher education and training agencies are also expected to help firms in recruiting highly qualified staff and upgrading employees' qualifications;

- Actively marketing the specific industrial strengths and raising awareness inside and outside the region which could improve the development framework of firms; 
- Locally providing certain services and advice to firms (e.g. finance, marketing, design) adapted to the particular field of specialization and local needs; and

- Attracting certain types of industrial investors to the locality via cluster-related marketing strategies according to identified gaps and weaknesses in existing value chains that need to be tackled in order to strengthen the entire production system.

In general, cluster promotion puts a stronger focus on ,soft' measures, such as facilitating contacts between various private and public actors and activating collective action, than on , hard' measures of concrete financial support (Nauwelaers, 2001, talks of a shift in focus from 'hardware' over 'software' to 'orgware'). It aims at improving the overall efficiency of local systemic interaction in the target sectors, mainly relying on consulting and moderation. As common practice shows, cluster-related measures are best tailored according to phases of development and lifecycle stages of clusters (Bruch-Krumbein and Hochmuth, 2000; Raines, 2001; European Commission, 2002). Regarding a recommended sequence of activities (e.g. OECD, 1999 and 2001), a first step comprises the analysis of regional industrial structures, based on data and expert interviews, which helps to identify existing sectoral specifisms and their strengths and weaknesses which need to be regarded in the design of suitable clusterenhancing measures. A second step that combines moderation and consulting aims at developing common sense and reducing barriers of conflict and competition in order to lay foundations for joint initiatives of potential cluster members. In a third step, concrete collaboration projects can be built upon the contact base which may eventually lead to an increased competitiveness of the entire set of clustered firms.

As per the emphasis on ,soft' instruments, key people play a crucial role in cluster promotion. Usually, central tasks of information provision, consulting and collaboration building are assigned to a competent individual or team that carries the function of an intermediary, contact broker or literally 'cluster management'. The rise of cluster-related strategies has in fact produced a new type of regional economic promotion officer, associated with new requirements regarding necessary qualifications. The people in charge need to be able to co-ordinate support across the boundaries of organizations for the sake of the overall functioning of the regional system in selected sectors, analyze linkages as well as launch and moderate joint initiatives, instead of just catering to the needs of individual firms or engaging in infrastructure planning. Activities in various fields must be integrated into a consistent approach that eventually targets to upgrade and further specialize an important part of the regional industrial and innovation system (Boekholt and Thuriaux, 1999; Nauwelaers, 2001).

\section{Categorizing institutional approaches of cluster promotion - a common framework}

Despite the depicted commonalities that mark a majority of cluster promotion strategies in Western countries, the picture of actual manifestations varies considerably across examples. ,As there is no agreed and shared definition of what a cluster is, it is hardly surprising that there is no one single model for such policy, and cluster labels are often attached to quite different sorts of policies' (Martin and Sunley, 2003, p. 23). This paper attempts to categorize ways of cluster promotion in order to help distinguishing modes of support according to their pattern of effectiveness. There have been comparative approaches that identify crucial elements and rationales of cluster policies, relate them to certain support requirements, and tell about their representation in various policy examples (Boekholt and Thuriaux, 1999; Roelandt et al., 2000; Raines, 2001; European Commission, 2002). What determines their effectiveness, however, has rarely been analyzed (Raines, 2002b), and Rosenfeld states (2001, p. 16): 
'To the best of my knowledge, there have been few attempts to evaluate cluster initiatives, which is somewhat surprising given the attention to evaluating network programs'.

One reason may be that effect-related aspects of distinction are not easy to find, seeing the manifold possible combinations of cluster measures, the widespread existence of mixed strategies that are difficult to clearly sort into juxtaposed categories, and the variety of sectorand place-specific contexts. One obvious difference between cluster initiatives concerns their scope and dimension regarding the number of included organizations and budget size. But, as Raines (2001, p. 11) states, 'scale is not necessarily the most important determinant of [cluster] policy' since qualitative aspects are more crucial than quantitative ones. A comparative judgment should therefore accentuate aspects of systemic quality (Raines, 2002b). This poses major challenges as it rather addresses the immaterial than the material dimensions of clusters which are hardly measurable (Steiner and Hartmann, 2001). Accordingly, our approach centers on the material aspect of institutional modes of cluster promotion, assuming that this comprises also major immaterial implications which decisively affect their success. We point out distinctly differing ways in which cluster promotion is set into motion and organized, also relating to sets of rules, norms, routines and culture (Nauwelaers, 2001). Still it needs to be explained why other options of distinction have been rejected.

Applying a system oriented view, differentiations of cluster promotion strategies could also be regarded with respect to certain cluster models possibly guiding political strategies. This relates, for instance, to three ideal types identified by Gordon and McCann (2000): the 'pure agglomerations economies model', the 'industrial complex model', and the 'social network model', which each emphasize other facets of cluster-related advantages. Similarly, the typology by Boekholt and Thuriaux (1999) distinguishing the 'national advantage', 'inter-firm networking', 'regional development' and 'industry-research' types of cluster policies could be used. Accordingly, different instrumental settings of cluster promotion may be evaluated against each other. In practice, however, support programs hardly follow a certain model but often combine several ones which renders effect-oriented distinctions extremely difficult (Raines, 2001; European Commission, 2002; Martin and Sunley, 2003).

This connects to the question whether the reliance of regional promotion on the cluster notion makes a difference anyway. Raines (2000 and 2001) and his project team have addressed this issue when comparing cluster policies in seven European regions according to the impact of the concept on a change of views and approaches of regional economic promotion. Their findings suggest that its influence on the ways in which regional policy is formulated and delivered is not large compared to that of general institutional and strategic environments (which supports our view; see also Nauwelaers, 2001). Hence, the fact that regional policy explicitly draws on the cluster idea hardly affects its success, yet sometimes leads to a higher integration of different policy themes and to more focused and systemic approaches (Raines, 2001). Martin and Sunley (2003, p. 24), however, doubt whether implementing regional policies under this label actually improves their effectiveness at all: 'In many cases it appears that the cluster framework is either unnecessary or even constraining'.

As this wider topic of debate has captured some scientific interest (see also Feser's, 1998, distinction between cluster-specific and cluster-informed policies), it is also picked up in our approach towards categorizing institutional forms of cluster promotion. In our interpretation, the decision to pointedly draw on the cluster idea or not is to some degree associated with certain features of institutionalization of a regional initiative; in principle, the one type tends to rest much more on the notion than the other. In this context, a first dimension of distinction 
demarcates explicit from implicit cluster promotion. The former term comprises all approaches which carry the cluster label and/or expressedly rely on that concept. It mainly relates to politically driven public schemes of regional economic promotion; here the fashion of picking up the cluster notion has most widely proliferated. Recent research on cluster policies and their evaluation has only concentrated on this variant (e.g. European Commission, 2002; Raines, 2002b). This overlooks that there are various initiatives which fall under the latter term of implicit cluster promotion; they follow the same objectives of regional sector-specific collaboration building, image creation, marketing and service provision, but are not consciously taking the cluster concept as a main orientation. These approaches predominantly emerge from other actor constellations and take other institutional shapes, for instance that of privately organized industrial associations or interest groups. The explicit/implicit dichotomy also appears to be pointed enough for allowing empirical investigations.

In connection with that, a second dimension of categorization is introduced which differentiates between top-down and bottom-up modes of cluster institutionalization. This captures the important aspect which actor types and constellations are the main drivers of cluster promotion and also has major implications regarding mechanisms and selected means of support, as will be outlined further below. The former term signifies the more or less ,typical' way how cluster policies are imposed onto parts of the regional economy by responsible public authorities with often little direct involvement of the actual subjects (firms, universities and other key organizations) in the design and implementation of measures. The second term acknowledges that initiative may as well predominantly emerge from, and be organized by, the true agents of cluster dynamics, notably industrial firms. Anyway, experience 'points to the importance of involving the local industry in policy design and implementation' (European Commission, 2002, p. 8; see also Roelandt et al., 2000). And the rise of cluster strategies generally tends to favor a greater involvement of private actors, although they hardly substantially fund explicit cluster programs (Nauwelaers, 2001; Raines, 2001 and 2002a). Gilsing (2000) has indicated the potential of 'cluster governance', the intended collective action of its members to upgrade the cluster, especially with regard to improving processes of innovation. Hence, we need to consider that there is a willingness and capability of self-organization of clusters which takes place outside the sphere of specific policy influences.

As the understanding of top-down and bottom-up is ambiguous, it needs to be pointed out that in the present case, this distinction does not relate to different interacting hierarchic levels of the political sphere, like local authorities and national ministries. In contrast, it attends to the juxtaposition of activities directed by public government (no matter of which spatial scale of responsibility), rather exogenous to the subjects of clustering, and those directly determined and controlled endogenously by the mostly private cluster members. Hence, our conception also deviates from the idea of bottom-up and top-down cluster policies introduced by Roelandt et al. (2000). In their case, the former term addresses the fostering of dynamic market functioning and removal of imperfections while the latter signifies government initiatives to set national priorities and future visions and to decide on the inclusion of actors.

Based on this common framework of categorization, different institutional forms of cluster promotion can logically be classified, graphically depicted in the coordinate system of figure 1. It allows to represent each case of cluster institutionalization as a specific combination of the selected categorical dimensions, with the one axis serving to position examples according to their quality as rather being implicit or explicit, and the other one signifying their bottom-up 
or top-down nature, including possibilities to differentiate degrees of attribution (in particular top-down cases are often also marked by certain bottom-up influences).

The four quadrants each comprise all approaches that belong to a certain institutional type: In the upper left section, explicit top-down modes of cluster promotion are positioned, such as all the labeled cluster policies. In the lower right section, implicit bottom-up initiatives have their place, where mostly private actors engage in regionally supporting their own group of industries widely unrelated to the conceptual background of cluster. These two antagonistic variants appear to be most common in the wider field of cluster promotion and probably bear interesting differences in implications, which is why they are picked up for further theoretical and empirical analysis. Figure 1 names the corresponding examples and positions them in the systemic framework (categorizing the Austrian approach as being very explicit, but not to the highest degree top-down, and the Euregio case as being very implicit and bottom-up). Besides that there are also implicit top-down cases where political authorities launch support programs which do not literally intend to foster clusters but indirectly trigger such effects, exemplified by the German 'BioRegio'-Scheme. The explicit bottom-up type of cluster institutionalization, which could be imagined as a pointed ,let's cluster' strategy employed by a number of regional firms and organizations apart from a political impetus, hardly exists in reality so far (taking up the interesting question why this is so is beyond the scope of this paper).

Figure 1: Categories of institutionalized cluster promotion

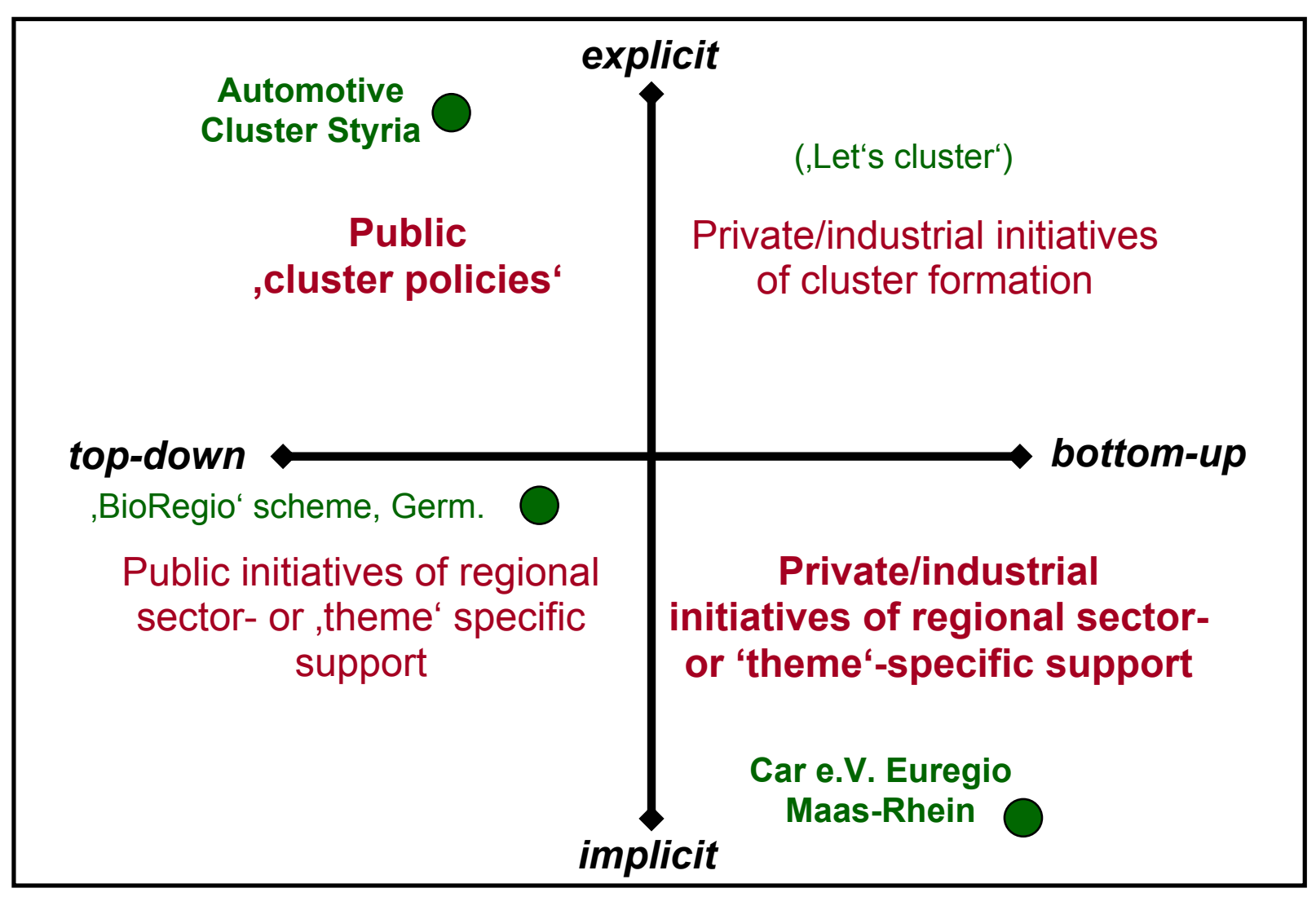

Source: Depiction by the author 


\section{How explicit top-down and implicit bottom-up cluster strategies differ}

The reason why institutional forms of cluster promotion have been categorized in the depicted way is that this is assumed to help identify principle differences in degrees and patterns of effectiveness. This relates in particular to the diametrical variants of explicit top-down and implicit bottom-up strategies, whose expectable implications are outlined in this section. An additional underpinning for taking up these two types of institutionalization comes from observations of practice. Regarding the development of clusters of a certain thematic orientation, some countries entirely count on designated policy programs and professional 'cluster managers' whereas in other countries the same objectives are predominantly taken up by industrial initiatives. As the different modes of promotion are often associated with the same sector group (in the case of our examples: automotive supply industries and R\&D organizations), this allows for discerning mainly institution-related differences in support effectiveness, widely disregarding the differentiating influences of specific structural features of included sectors (the caveat of nonetheless differing finer structures of various regional concentrations of automotive supply firms will be dealt with in our empirical project).

The following subsections elucidate major aspects in which explicit top-down and implicit bottom-up modes of cluster institutionalization differ. As general systemic issues shall be highlighted, the discussion abstracts from sector-specifities. Assumingly, the compared types of support bear different implications with regard to four main fields: Institutional genesis and composition of the actor group, structures of finance and decision making, preferred target areas and support measures, and, consequently, probable effects of increased innovativeness and competitiveness. For the sake of simplification, abbreviations are used for addressing the explicit top-down approaches (ETs) and implicit bottom-up variants (IBs) in the following.

\subsection{Institutional genesis and composition of the actor group}

Right from the start, the juxtaposed institutional types of cluster promotion provide a different setting for the entire effort. Relevant points appear to be the initiation and genesis of the respective scheme, the composition of included organizations, the spatial reach and mode of regionalization of the initiative, and the sectoral reach and flexibility regarding the selection of industries to be integrated.

Regarding the issue of genesis, ETs mainly emerge from the political sphere (yet often with some involvement of private actors) where wider considerations of regional economic development, a higher orientation towards internationally 'fashionable' concepts of policy making and also election- and party-related considerations represent important drivers of the cluster strategy. IBs, in contrast, are triggered by perceived real needs of a group of firms to start a targeted industrial initiative, no matter what theoretical foundation is offered by the science and policy world. In short, creating the essential cluster-related effects to the inside is the major impetus for IBs, while ETs (also) have a strong eye on the policy marketing effect to the outside. ETs, however, draw on a stronger analytical base since governments usually carry out (or have professionals conduct) in-depths investigations of various cluster-related features of the targeted economic community before implementing concrete measures. IBs rather take a spontaneous, less well-reflected start. There may also be a difference in the number of initiators. IBs usually combine a group of first actors from various organizations; ETs are started by one or a few members of the top political level. Differences in the formal set-up add to the picture. The governing of ETs is mostly integrated into regional administrative structures 
while IBs take the form of private registered associations or companies. This has implications for the relationship with cluster members which are explained below.

The institutional differences affect the way in which the composition of members evolves. As ETs have a mission relating to a crucial segment of the entire regional economy, all potentially includable firms and organizations according to the preset definition of target sectors are addressed from the beginning. Within the reach of administrative boundaries, all actors who are willing can take part, potentially also integrating a large range of non-industry actors. Set against this inclusive strategy, IBs carry a more exclusive 'club' character and the number of members slowly evolves though the gradual attraction of more and more partners that register to the initiative. Although there is a high interest to integrate non-industry actors (above all university institutes), the range may be smaller than in the case of ETs, but the selection is more focused towards objectives of innovation and competitiveness. Due to financial reasons, IBs also have an interest to source large numbers of members, which results in an openness to new entries. The evolution of memberships here probably often occurs according to the preexisting contact network of earlier members, which creates a group of organizations already linked to each other to some degree - a good basis for important cluster effects to emerge. In sum, however, IBs tend to selectively include relatively strong agents which somehow contradicts to common objective of cluster strategies to have a wider, yet targeted upgrading impact; cluster promotion 'should aim to provide services that all firms merit access to, whether they are clustered or not' (Enright and Ffowes-Williams, 2001, p. 5).

Particularly interesting differences of ETs and IBs can be pointed out with respect to the determination of memberships boundaries. This relates to questions which generally feature prominently in the discussion on cluster policies: 'Which firms should be left out? How far upstream and downstream of the 'core' cluster activity should policies extend?' (Martin and Sunley, 2003, p. 24). In this regard IBs show advantages in shaping the group of cluster members according to suitable functional patterns, rather than to pre-determined normative and formal demarcations. This relates both to the spatial reach of the cluster and to its sector composition.

Whereas ETs, due to the fixation of the responsible public agency to a distinct administrative region, can just cover developments and include units which locate in that area, IBs easily reach beyond that border, depending on the engagement of actors that want to be part of the initiative. Here, the spatial boundary of memberships can flexibly be regulated by the group itself, and due to another logic of inclusion the functional aspect may generally have a priority over that of formal location. The postulation by Enright and Ffowes-Williams (2001) that cluster policies should be delivered by the governance level most closely matched to the geographical extent of the cluster can easier be fulfilled by non-political IBs. Consequently, IBs appear to be better positioned than ETs in admitting important external influences to the cluster, a requirement that is closely connected with the ability of clusters to stay creative and innovative in a global-local context (Nauwelaers, 2001; European Commission, 2002).

Similarly regarding the selection of integrated industries, ET policies tend to determine quite accurately which sector(s) ought to get included into and be eligible for promotion. This choice is usually incorporated in the brand name of the policy scheme. Responsible agencies often lack the financial abilities or system related knowledge to open up cluster programs to a wider range of sectors which would allow for the important combination of a more diverse set of complementary and value-chain-related manufacturing and service industries. Hence, they can hardly fulfill the requirement of effective cluster promotion to use and increase synergetic 
regional economic potential and to reduce risks of over-specialization (Bruch-Krumbein and Hochmuth, 2000). IBs, in contrast, operate without such constraints and are usually more flexible in changing selection strategies over time. Memberships develop according to common interest with respect to a certain 'theme' which can be attractive for various types of industries. As financial funds grow in line with the number of members, there are no preset limitations by a fixed budget. Consequently, IBs possess better potential than ETs to constitute complexes of interacting agents that are in line with major features of an ideal cluster in terms of a functional entity that crosses administrative regional boundaries and official sector demarcations (Martin and Sunley, 2003) and enables 'symbiotic interdependence based on synergism’ by comprising dissimilar firms (Roelandt and den Hertog, 1999, p. 12).

\subsection{Structures of finance and decision making}

Regarding the operational side of cluster promotion, ETs and IBs display differing features with respect to fundamental means of finance and routines of decision making, which probably influences their effects. Major points that need to be addressed are the overall model of finance and organization, structures of decision making and control, and the motivation of participating organizations and acceptance of initiated measures by cluster members.

The most obvious finance-related difference between ETs and IBs is that the former relies on public money, the latter on private funds provided by its members. This simple distinction may have major implications. In order to install ETs, an early conceptualization of the cluster strategy and application for adequate funds within the administrative system is necessary. In times of tight state finance, the approved budget is probably smaller than had been applied for, leading to an operational situation of financial constraints. IBs, whose budget grows correlated to the number of contributing and integrated actors, have more flexible and less restricted financial possibilities. However, the exit of members may quickly and unexpectedly reduce funds and jeopardize planned activities. Regarding the financial time horizon, ETs can usually only rely on public funds for a certain promotion period of a few years (idea of a 'thrust' initiative) while IBs are meant to have a longer term financial base. ETs are also expected to carry on after the public funding period, but have to undergo an organizational transformation. As this surely implies some kind of rupture (finance, personnel, label, work routines), the initiative may be negatively affected. The actual work organization, however, probably does not differ much between ETs and IBs as both count on the engagement of a key official who takes over all of the mostly 'soft' tasks in an integrated approach, as generally signifies cluster promotion. To which extent this intermediary is assisted by a team rather depends on the size of the budget than the institutional model.

Different forms of financial organization are associated with different structures of decision making. IBs, in the form of registered associations, are highly influenced by the paying members, especially those that constitute the board or other supervising councils. Their power of deciding about what will be done and how it is done is relatively high compared to that of the employed key official. Hence, main initiatives can actually emerge out of the group of cluster firms. As per the reliance on private money, no official supervision or control by political bodies is obligatory. The executives or 'cluster managers' of ETs, in contrast, appear to have more decision power, at least in relation to the promoted actors which have smaller options to directly govern activities in their own cluster. Yet, upper political authorities can exert a decisive influence, in fact may often continuously control the performance of the cluster management they finance. Due to the embedding of ETs into higher level political strategies of re- 
gional governments, there may be a strong monitoring 'from above' whether the cluster initiative produces the promised (and politically marketable) results.

Differences in financing and decision making can be expected to also affect the motivation of actors and the acceptability of cluster-related measures. When the subjects of promotion pay for an imitative, as in the case of IBs, they have probably a higher interest in knowing about what is going on and using the offered services. Having options to directly participate in the conceptualization of measures, members may be strongly inclined to accept and attend cluster-enhancing actions. There are also better chances that feelings of pride and a sense of belonging develop, which strengthens the image and identity aspects of the emerging cluster. Under the conditions of ETs, however, it may be more difficult to raise active participation of a larger share of targeted organizations (Nauwelaers, 2001, p. 106, mentions 'the atmosphere of mistrust between public and private actors that often prevails in regions'). Although firms could profit from the cluster strategy for free since its measures are publicly paid for, there may be certain barriers to attendance due to feelings of remoteness, of not really being concerned. Central objectives of cluster promotion are more difficult to achieve as the cohesion between regional agents, including the cluster management, is not strong enough.

\subsection{Preferred target areas and support measures}

The depicted institutional differences of ETs and IBs can also be associated with distinctions regarding the actual content and constellation of cluster-related measures. This concerns issues of strategic orientation, preferential structures with respect to the application of various means of cluster support, and the variability of the programmatic set of instruments.

As regards the strategic perspective, ETs appear to be advantaged relative to IBs. Due to the strong link with political authorities and programs, cluster policies are usually well integrated into wider strategies of regional economic development. The objective of transforming selected industrial structures towards a conceptual ideal helps to focus and expediently integrate promotion measures (Raines, 2001). Instruments are designed for addressing a maximal number of targeted regional actors, and generally the ETs' cluster strategy probably bases on a more holistic view of regional development than that of IBs. In the latter case, agents may prioritize to support the competitiveness of individual firms by better embedding them in the regional collective, but not to strengthen the wider collective system as such. This perspective has it good sides, too. As company dynamics are more considered in IBs, there is less danger of an overly fixation of the strategy on just the regional context and a neglect of factors inside firms and outside of the region, as ETs are accused for (Martin and Sunley, 2003). In IBs, vital factors of corporate development are probably more comprehensively addressed; firms are not mistakenly seen as being predominantly determined by the local framework and clusterspecific aspects. When policies of regional economic promotion put too much emphasis on cluster promotion in the sense of ETs, this may even be detrimental as it can lead the region into a lock-in situation and industrial uniformity and cause a lack of diversity which inhibits innovation and the ability to positively react to radical technological shifts (Bruch-Krumbein and Hochmuth, 2000; Martin and Sunley, 2003).

Despite the institutional differences, the type of measures taken by ETs and IBs may be surprisingly similar. Providing an integrated package of information supply, public relation work and, above all, improving collaboration among firms and of firms with R\&D partners is a major task for both of them, in line with the general elements of cluster promotion. However, there could be distinctions regarding preferences or the relative importance of combined 
instruments because of differing contact-related starting points and constellations of objectives. IBs may have an interest to focus on the intensification and effectuation of functional linkages, also with regard to innovative interaction, whereas ETs rather try to enlarge the contact network as such and engage in the creation of social and informal relationships that potentially entail formal co-operation. One area of activity where ETs are expected to substantially differ from IBs is location marketing. ETs are better positioned to address the attraction of investors from outside and to support new firm formation, decisively enriching the cluster's synergetic and innovative potential. They can combine cluster measures with infrastructural means of technology oriented regional promotion, notably science parks and technology incubators, as recommended by Nolan (2002). This is associated with stronger image-creating and branding powers of a politically supported initiative. IBs, although also interested in marketing the represented industrial strength to the outside, are probably not eager to support the regional mushrooming of potential competitors of their member firms. They may, however, contribute to the attraction of major customers to the locality. And due to their 'club' character and relatively strong internal cohesion, IBs have options which are hardly imaginable for ETs, for instance, that a collective of member firms guarantees a bank loan provided to another member with a short term credit demand.

IBs generally seem to be advantaged in terms of a greater programmatic variability and flexibility. They are neither bound to the cluster concept nor to political prescriptions and the restrictions of public and planned funding. This is why they are more independent than ETs when it comes to the necessity to modify instruments or to take up new fields of activity. Offered services can more quickly be adapted to the changing needs of member firms as communication ways are short and response may be fast. This flexibility also applies to the institutional shape as such which can quite easily be changed when new chances come up (founding of an institutional appendix) or others vanish. ETs, however, tend to stick to one programmatic trajectory once the major decisions on cluster objectives have been stated.

\subsection{Probable effects of increased innovativeness and competitiveness}

Eventually, the collected arguments of distinction provide some reasons to expect that ETs and IBs also differ with regard to achieved cluster-related effects concerning aspects of regional collaboration, corporate competitiveness and innovativeness. Assumptions on such implications, however, can only be made with considerable reservations. When looking at the actual development of promoted clusters, no matter which institutional model stands behind that, it is extremely difficult to tell whether certain results can be attributed to the promotion strategy or to the large number of other factors that affect regional economic dynamics, including influential external ones. Hence, there is the problem to clearly discern the effects we are looking for. An option for measuring effectiveness could be to determine the success of cluster strategies against the claims generally associated with the concept. This sets high standards as clusters are expected to 'raise the productivity, innovativeness, competitiveness, profitability, and job creation of their constituent firms, of the geographical areas in which the clusters are located, and hence of the wider national economy' (Martin and Sunley, 2003, p. 22). Yet, to the opinion of these authors, empirical research has so far not been able to convincingly prove that clusters really fulfill such aspirations. Being aware of the depicted problems of evaluation and evidence, we try to carefully state a few assumptions regarding the expectable differing results of the compared modes of cluster institutionalization. In some way they summarize over the points of discussion raised in the three subsections above. 
With regard to the central issue of collaboration, IBs may be more effective in activating functional relationships between complementary firms and from firms to R\&D partners, whereas ETs manage to create a larger number of new contacts which, however, may not immediately be productive. Consequently, IBs more directly enable and foster innovation-enhancing relationships than ETs and bear a higher potential of actually producing innovative results. As the support of company competitiveness has higher preference in the case of IBs than ETs, the former may have a lead in effectiveness over the latter in this regard, too. Accordingly, IBs more than ETs tend to increase intraregional disparities. ETs, in contrast, follow a broader claim of influence and, hence, could induce higher positive impacts on the entire targeted regional system, including important impulses of restructuring. They definitely have the chance to purposefully take advantage of the popular brand value of the cluster label, profiting from Porter's exceptional skills in creating a world market success. The signal value of the term should not be underjudged as it evokes the image of a highly productive, knowledge-rich, entrepreneurial and socially progressive economy (OECD, 1999; Martin and Sunley, 2003). The inflationary use of the label, however, has already started to turn positive associations into the opposite. Ultimately touching the question of efficiency and the relation of costs to benefits, it must clearly be stated that IBs feature better than ETs: They can realistically be expected to create major cluster advantages, but at no direct public cost.

\section{Empirical verification: Comparing car e.V. and the Automotive Cluster Styria}

An empirical verification of the discussed distinctions between the ET and IB modes of cluster institutionalization is currently under way. ${ }^{1}$ In the following, the selection of case studies and the methodological approach are explained. The algorithm of our approach reminds of the framework of evaluation proposed by Raines (see figure 2). Project results, however, are not presented here because only a minor share of the planned field work has been completed so far. Yet, findings can be expected to corroborate the depicted assumptions.

\section{Figure 2: Steps in evaluating cluster policies}

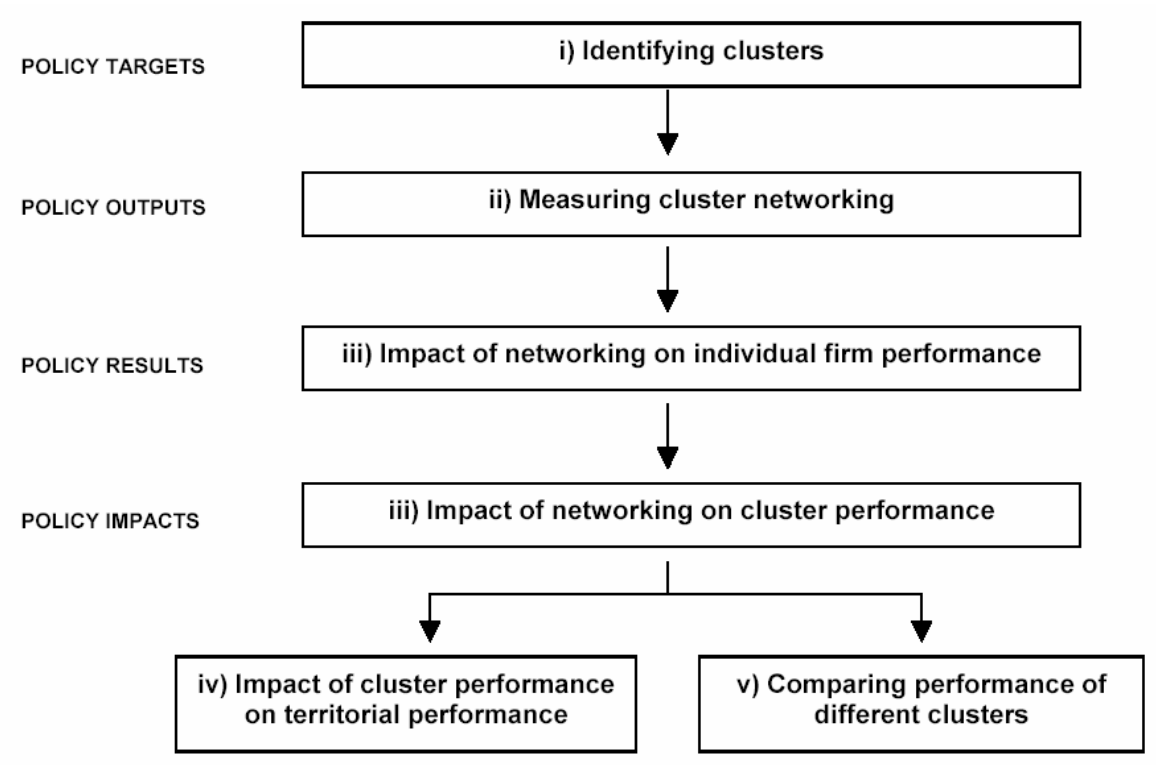

Source: Raines, 2000b, p. 11

\footnotetext{
${ }^{1}$ We gratefully acknowledge a project funding provided by the 'Stiftungs- und Förderungsgesellschaft' of the University of Salzburg.
} 
As the project attempts to point out implications of distinct institutional modes of cluster promotion, it is tried to exclude the influences of differing industrial sectors as far as possible. This can be done by selecting case studies which relate to the same group of sectors but differ with regard to the institutionalization of cluster promotion. In this context, initiatives addressing automotive supply industries offer good options for investigation. First, firms in this field generally show tendencies towards regional concentration and clustering due to ,lean management', increased vertical disintegration and importance of systemic collaboration, which is true for Europe (Hudson and Schamp, 1995) and other countries (e.g. Klier, 1999, on the US American 'auto corridor' extending from Michigan to Tennessee). Second, this set of sectors appears to be a favorite field of innovation-oriented cluster promotion in central Europe and beyond, both in the form of ETs and IBs (a google search on 'automotive cluster' produces about 442,000 entries). And third, the theme of automotive supplies has the advantage of not only comprising one particular sector but various manufacturing and service industries that need to complementary combine activities in order to create a common type of product, automobiles. Firms belong to different stages and 'tiers' of a complex value chain. Consequently, this set of related sectors is quite consistent with general cluster-related assumptions.

The following 'matched pair' of cluster initiatives for automotive supply firms has been selected for empirical investigation: The private association car/competence center automotive region Aachen/Euregio Maas-Rhein e.V. (Germany/Netherlands/Belgium) provides a distinct example of an IB initiative, stretching across international borders. In Austria, where cluster policies have become a particular fashion, the Automotive Cluster Styria, a prominent 'flagship' supported by the state government, is studied as an example of ETs (although an active engagement of key firms clouds the picture of a pure top-down approach). The latter initiative, in contrast to the former, has received some scientific attention, yet not undergone indepth investigations so far (Bergman and Lehner, 1998a; Steiner and Hartmann, 1998; Tödtling, 2001). Besides the sectoral orientation of cluster promotion, the study regions bear other common features. Both have a longstanding industrial tradition as locations of automotive supply firms, but have been subject to specific promotion just for a couple of years. Both regions have a well developed infrastructure of higher education and research that is related to the respective industrial field. Nonetheless, automotive supply industries in Styria and the wider Aachen region are marked by considerable differences concerning the nature and size structure of firms, their position in the automobile production system, and the relative importance of these industries for the regional economy, which need to be taken into account in the research project. Yet, analysis concentrates on aspects where interregional comparison is possible and reasonable: Selected characteristics of the institutional form of cluster promotion and directly derivable effects.

Research is carried out by personal qualitative interviews with cluster executives and other experts in the realm of the initiative, on the one hand, and by semi-standardized interviews with the managers of a number of cluster member firms, on the other one. In the first instance, it is planned to include 5 experts and 15 firms in each study region. They are selected according to the objective to include actors of a variety of sectors and with a sufficiently long cluster membership for being able to judge on effects. Questions to firms relate to their way of entry into the initiative, the relative pros and cons compared to other means of regional industrial support, and a wide array of effect-related aspects, as those must be regarded the most important 'output' of cluster promotion (Raines, 2002b). In spring 2004, a large part of the investigations regarding car e.V. could be completed. The Styrian case, however, has not been exam- 
ined yet (in general, the lack of earlier in-depths studies on actual effects of this initiative stands in stark contrast to the high public attention it receives; Tödtling, 2001).

It is therefore not possible to present first insights from a comparative perspective. The findings relating to the Aachen/Euregio case of IB promotion, however, hint at relatively high levels of activity, involvement and satisfaction of visited member firms. Regarding effects of the initiative, close to every respondent has gained in terms of additional contacts and collaborations. And over half of them tell that their membership as also brought some (small) benefit for corporate innovativeness. Compared to the quite skeptical views on the success of cluster promotion expressed by some researchers, this result is truly remarkable.

\section{Conclusions}

When Martin and Sunley (2003, p. 28) state that 'even cluster enthusiasts find it enormously difficult to point to any examples of deliberate cluster promotion programmes that have been unambiguously successful', this may just be an indication that research has not looked at the right examples. When the meaning of cluster promotion is taken up more broadly, also including approaches that are in their substance, yet not in their form, oriented towards the conceptual model, the results may be surprising. This paper puts forward the assumption that the usually investigated institutional forms of explicit top-down official cluster policies may in principle be less effective than implicit bottom-up initiatives, i.e. regionally oriented thematic industry associations which are actually governed by larger groups of firms and neither rely on the cluster notion nor on public support. They may be the more adequate way of institutionalization as 'clustering and networking basically is a bottom-up, marketinduced and market-led process' (Roelandt et al., 2000, p. 14). Their positive impacts appear to cover all aspects that are usually seen as crucial outcomes when evaluating cluster programs (Raines, 2002b): Increased exchange of information and cohesion of regional economic and research organizations, more collaboration in order to fulfill the quality requirements of customers, more visibility and image of the industry group inside and outside the region, and even, to a small extent, higher competitiveness and innovativeness. And the best is that all this can be achieved without spending one public cent. Hence, should we advise all public agencies of regional promotion to step back and just wait (or pray) for localized companies to get the right idea of starting a strategy of regional thematic support?

No, the conclusion can not be so pointed, and the choice between the two modes of institutionalization is definitely not that easy. Although implicit bottom-up approaches appear to be favorable to some degree, public cluster programs also have their specific relative strengths. As the former may better activate cluster effects of existing and included firms and other organizations, the latter have better potential to increase the inclusion of a wider set of actors and the emergence of new ones. Consequently, whether the one or the other institutional mode of cluster promotion is adequate depends on the specific regional situation regarding structural preconditions and preferred objectives. Our argumentation once again confirms that there is no universal 'blueprint' of best practice in cluster promotion that can be applied to a large set of regions (European Commission, 2002; Martin and Sunley, 2003).

But in which regional situation is it more advisable to employ explicit top-down strategies, and where, in contrast, can the advantages of implicit bottom-up initiatives bear better results? Although the hitherto poor state of evidence of our argument hardly allows for an answer, we may state the following conclusion: Initiatives induced and executed by industrial actors can only bear success if there are enough of them who are willing to participate. When this is the 
case and there is a sufficiently large set of 'first movers', like in an industrially rather mature area, implicit bottom-up approaches may in fact be advantageous in fostering regional collaboration and innovation. But when there is more need to enrich the regional economic structure with respect to firms of a particular sector group and where many of the present actors have so far been operating isolated from each other, explicit public cluster policies may be the better choice, also in terms of their higher signal value. Anyway, some authors see a main role of cluster policies in concentrating on the formation of new firms and investing in education and support infrastructure (Breschi and Malerba, 2001), which is something that private associations can not do. A simultaneous combination of both forms of cluster promotion in one region and relating to the same set of industries, however, is not recommendable. This bears the danger of creating counterproductive irritations among firms and cluster executives (as experience from the Euregio case study suggests). What may be a promising way of conjunction is a time phase sequence of a first period of official cluster policy (where necessary), followed by a phase of letting industries organize the evolution of dynamics themselves, in line with lifecycle aspects of the cluster. In any case, the question of effective institutional forms of cluster promotion offers wide scope for further conceptual and empirical refinement.

\section{References}

Baptista, R., 2002, Do innovations diffuse faster within geographical clusters? International Journal of Industrial Organization, 18, pp. 515-535.

Baptista, R., and Swann, P., 1998, Do firms in clusters innovate more? Research Policy, 27, pp. 525-540.

Bergman, E.M. und Lehner, P., 1998a, Industrial Cluster Learning Plattforms. Methodology and Case Studies of Four Local Austrian Industry Clusters. SRE-Discussion 64, Department of Urban and Regional Development, Economic University Vienna.

Bergman, E.M. und Lehner, P., 1998b, Industrial Cluster Formation in European Regions. U.S. Cluster Templates and Austrian Evidence, SRE-Discussion 65, Department of Urban and Regional Development, Economic University Vienna.

Boekholt, P. and Thuriaux, B., 1999, Public Policies to Facilitate Clusters: Background, Rationale and Policy Practices in International Perspective, in: OECD (ed.), Boosting Innovation: The Cluster Approach, Paris, pp. $381-412$

Breschi, S., and Malerba, F., 2001, The Geography of Innovation and Economic Clustering: some introductory notes, Industrial and Corporate Change, 10(4), pp. 817-833.

Bruch-Krumbein, W., and Hochmuth, E., 2000, Cluster und Clusterpolitik. Begriffliche Grundlagen und empirische Fallbeispiele aus Ostdeutschland, Schüren, Marburg

Cluster Navigators Ltd., 2001, Cluster Building: A Toolkit. A Manual for starting and developing local clusters in New Zealand, Wellington.

Enright, M., and Ffowes-Williams, I., 2001, Local partnership, clusters and SME globalisation, OECD Workshop paper, Paris (avialable under www.oecd.org).

European Commission, 2002, Regional Clusters in Europe, Observatory of European SMEs 2002/no. 3, report coordinated by A. Isaksen and E. Hauge, Brussels.

Feser, E., 1998, Old and new theories of industry clusters, in Steiner, M. (ed.), Clusters and Regional Specialisation. Pion, London. 
Gilsing, V., 2000, Cluster Governance. How clusters can adapt and renew over time, paper prepared for the DRUID PhD-conference, Copenhagen, Jan. 2000. Erasmus University, Rotterdam.

Gordon, I.R., and McCann, P., 2000, Industrial clusters: complexes, agglomeration and/or social networks? Urban Studies, 37(3), pp. 513-532.

Held, J.R., 1996, Clusters as an economic development tool: beyond the pitfalls, Economic Development Quarterly, 10(3), pp. 249-261.

Hudson, R., and Schamp, E.W. (eds.), 1995, Towards a New Map of Automobile Manufacturing in Europe? New Production Concepts and Spatial Restructuring, Springer, Berlin.

Keeble, D., and Wilkinson, F. (eds.), 2000, High-Technology Clusters, Networking and Collective Learning in Europe. Ashgate, Aldershot.

Klier, T.H., 1999, Agglomeration in the U.S. auto supplier industry, Economic Perspectives, Federal Reserve Bank of Chicago, 23(1), pp. 18-34.

Lagendijk, A., 1999, Innovative Forms of Regional Structural Policy in Europe: The Role of Dominant Concepts and Knowledge Flows, in: Fischer, M.M. et al. (eds.), Innovation, Networks and Localities, Springer, Berlin, pp. 272-299.

Mariussen, A. (ed.), 2001, Cluster Policies - Cluster Development? Nordregio Report, no. 01/2, Stockholm.

Martin, R., and Sunley, P., 2003, Deconstructing Clusters: Chaotic Concept or Policy Panacea? Journal of Economic Geography 3, pp. 5-35.

Moulaert, F., and Sekia, F., 2003, Territorial Innovation Models: A Critical Survey, Regional Studies, 37, pp. 289-303.

Nauwelaers, C., 2001, Path-Dependency and the Role of Institutions in Cluster Policy Generation, in: Mariussen, A. (ed.), Cluster Policies - Cluster Development?, Nordregio Report 2001/2, Stockholm, pp. 93-107.

Nolan, A., 2002, Public Policy on Enterprise Clusters and Networks, in: Bartlett, W., et al. (eds.), Small Enterprise Development in South-East Europe: Policies for Sustainable Growth, Kluwer Academic Publishers, Boston, pp. .

OECD, 1999, Boosting Innovation: The Cluster Approach, OECD, Paris.

OECD, 2001, Innovative Clusters: Drivers of National Innovation Systems, OECD, Paris.

Perry, M., 1999, Clusters last stand, Planning Practice and Research, 14(2), p. 149-152.

Porter, M., 1990, The Competitive Advantage of Nations, Macmillian, London.

Porter, M., 1998, Clusters and the new economics of competitiveness, Harvard Business Review, December, pp. 77-90.

Porter, M., 2000a, Locations, clusters and company strategy, in: Clark, G.L., Feldman, M., and Gertler, M. (eds.) Oxford Handbook of Economic Geography, Oxford Univ. Press, Oxford, pp. 253-274.

Porter, M., 2000b, Clusters and government policy, Wirtschaftspolitische Blätter, 47(2), pp. 144-154.

Raines, P., 2000, Developing Cluster Policies in Seven European Regions, Regional and Industrial Policy Research Paper No. 42, European Policies Research Centre, University of Strathclyde, Glasgow.

Raines, P., 2001, The Cluster Approach and the Dynamics of Regional Policy-Making, Regional and Industrial Policy Research Paper No. 47, European Policies Research Centre, University of Strathclyde, Glasgow.

Raines, P. (ed.), 2002a, Cluster Development and Policy, Ashgate, Aldershot.

Raines, P., 2002b, The Challenge of Evaluating Cluster Behaviour in Economic Development Policy, paper presented at the International RSA Conference on 'Evaluation and EU regional policy: New questions and challenges', May, Glasgow.

Roelandt, T.J.A., and den Hertog, P., 1999, Cluster Analysis and Cluster-Based Policy Making in OECD Countries. An Introduction to the Theme, in: OECD (ed.), Boosting Innovation: The Cluster Approach, Paris, pp. 9-23.

Roelandt, T.J.A., Gilsing, V.A., and van Sinderen, J., 2000, New Policies for the New Economy. Cluster-based Innovation Policy: International Experiences, paper presented at the 4th Annual EUNIP Conference, 7-9 December, Tilburg. 
Rosenfeld, S., 2001, Backing into Clusters: Retrofitting Public Policies, paper presented at the John F. Kennedy School Symposium, Harvard University, March 29-30; OECD, Paris ( available under http://www.rtsinc.org/ publications/Harvard4\%20doc\%20copy.pdf).

Rosenfeld, S.A., 2002, Creating Smart Systems. A Guide to Cluster Strategies in Less Favoured Regions. Paper presented at a seminar on European Union Regional Innovation Strategies, Brussels (available under http:// europa.eu.int/comm/regional_policy/innovation/pdf/guide_rosenfeld_final.pdf).

Steiner, M. (ed.), 1998, Clusters and Regional Specialisation: On Geography, Technology and Networks, Pion, London.

Steiner, M., and Hartmann, C., 1998, Learning with clusters: a case study from Upper Styria, European Research in Regional Science, 8, pp. 211-225

Steiner, M., and Hartmann, C., 2001, Looking for the Invisible: Material and Immaterial Dimensions of Clusters. Paper presented at the Regional Studies Association Annual Conference on 'Regionalising the Knowledge Economy'. November 21, London.

Tödtling, F., 2001, Industrial Clusters and Cluster Policies in Austrian Regions, in: Mariussen, A. (ed.), Cluster Policies - Cluster Development?, Nordregio Report 2001/2, Stockholm, pp. 59-78. 